\title{
Influence of Canopy Geometry in Spray Deposition and IPM
}

\author{
F.R. Hall \\ Laboratory for Pest Control Application Technology, The Ohio State University, Wooster, OH 44691
}

Pesticides are expected to continue to play a major role for the foreseeable future in protection of most crop systems from insect and disease damage. Improvements in chemical approaches that must also safeguard the environment can be included under the following: 1) intrinsic activity of the active ingredient; 2) efficiency of use; 3) selectivity; 4) resistance of target organism; and 5) compatibility with other control measures (Graham-Bryce, 1983).

Increased concern about pesticide pollution, development of resistance to pesticides, more expensive pesticides, recent advances in low volume spraying, and integrated pest management make it important that we apply the correct amount of pesticide on the foliar target. Lack of precise pesticide recommendations can result in pesticide applications that are more costly, monetarily and environmentally, than they should be. Application techniques, pesticides, and orchard systems have changed, but the concepts of calibration, equipment, and spraying efficiency have not kept pace. The crop sprayer today is basically the same as it was 30 years ago-liquid container, pump, and nozzles. Chemicals have changed dramatically, however, with increases in efficiency of up to 20-fold over the standards of just 10 years ago. The capability to deliver reduced amounts of agrochemicals remains suspect, numerous researchers estimating only " $1-2 \%$ of the original mixture arriving at the target site of action" (Hall, 1985).

Geissbuhler et al. (1987) predicted that future activities for research in agrochemicals will be governed by factors including: 1) advances in the knowledge of crop biochemistry and pest biology, 2) decreased successes in conventional approaches, 3) increased use of electronic information and data development and transfer, and 4) increased economic and ecological pressures leading to modified crop technology and regulatory environment. As a consequence of this concern about the environment: 1) biotechnology should become an increasing component of agricultural research, 2) more "biorational" designs of pesticides will be developed, along with 3) more sophisticated evaluation systems, and 4) additional targetoriented delivery systems (improved accuracy in placement of the toxicants).

\section{RATIONALE FOR CHANGE}

Bukovac (1985) listed some trends in fruit production that are creating changes in spray application technology: Orchard designs make greater use of small trees in high-density plantings; changes in tree form as a result of new genetic material (e.g., dwarf, spurtype) or cultural practices (e.g., pruning and training systems); increased requirement for a more precise delivery of a predicted dose of the pesticide over the target area; shift from traditional highvolume to low-volume spraying systems; an array of atomizers from

Sincere appreciation is extended to colleagues D.C. Ferree (Horticulture), H.R. Krueger (Entomology), D.L. Reichard, (Agr. Engineering), and R.D. Fox (Agr. Engineering) who greatly contributed to these studies via their participation in various LPCAT research investigations. hydraulic to air shear, spinning disc, and rotary nozzles; increased adoption of integrated pest/crop management programs.

The most striking changes involve a significant increase in tree density. Thus, tree size has become smaller and tree shape and canopy geometry involve less of a problem for even coverage. Central leader pruning and spur type cultivars have also modified foliage and branch configurations within the trees, making spray penetration easier. Finally, perhaps just as important, the increase in the number of rows/ha has increased success in developing new classes of crop protection agents in agriculture.

In the orchard, the target is complex. The target may be an insect, pathogen, mite, leaves, fruit, etc. In addition, the pest location within the canopy may be quite variable, i.e., outside, inside, top center, etc. Tree sizes and shapes change during an individual growing season as well as during the life span of the trees. The extent of foliage volume per hectare has been estimated to be up to 18fold greater than the land area it occupies (Forshey et al., 1983; Morgan, 1964). Thus, with increasing foliage/ha, land area takes on less meaning as the basis for recommendation for spray volume and dose. The target area needing protection becomes more important as we attempt to balance needs and practical solutions to problems of using pesticides to produce a high quality horticultural crop.

Another estimate of target volume in a plant canopy is defined by leaf area index (LAI), which is the ratio of the total area above ground divided by the ground area in which the crop grows. In addition, in some dense crops (citrus), it is recognized that the density of the surface area in the periphery can be 10 times higher than in the center of the canopy, which suggests adjustments are needed in application techniques. The openness of most modern apple plantings with well-balanced color/yield requirements, however, is much easier to spray than the older $(14 \times 14 \mathrm{~m})$ plantings.

The delivery of a crop protection agent to a crop is composed of a complex series of events (Fig. 1) (after Young, 1979). The various phases of this series of interacting events have not been well studied, perhaps because biologists and engineers each think it is more appropriate for the other discipline. The complexity of these interesting events is an example of the need for multidisciplinary research and development, which, in spite of the frequent rhetoric from university deans, etc., the academic institutions have had only moderate success in accomplishing. Integrated pest management (IPM) is frequently noted as a way to reduce pesticide usage. It can indeed be that, but the requirements for increased knowledge about the type of pest problem, its intensity and occurrence, and then treatment as needed within different blocks of trees also present the potential for increased use of pesticides. The reduction of a "reliance on insurance" spraying of fruit presents serious management/ resource difficulties for most growers. What is it that they are now required to see, identify, and make a judgment upon? This change requires additional training for those growers who, because of the isolated nature of their farms, are not able to engage a consultant or participate in a scouting program. Specific pest problems require selective treatments, thus the need for increased knowledge. The 


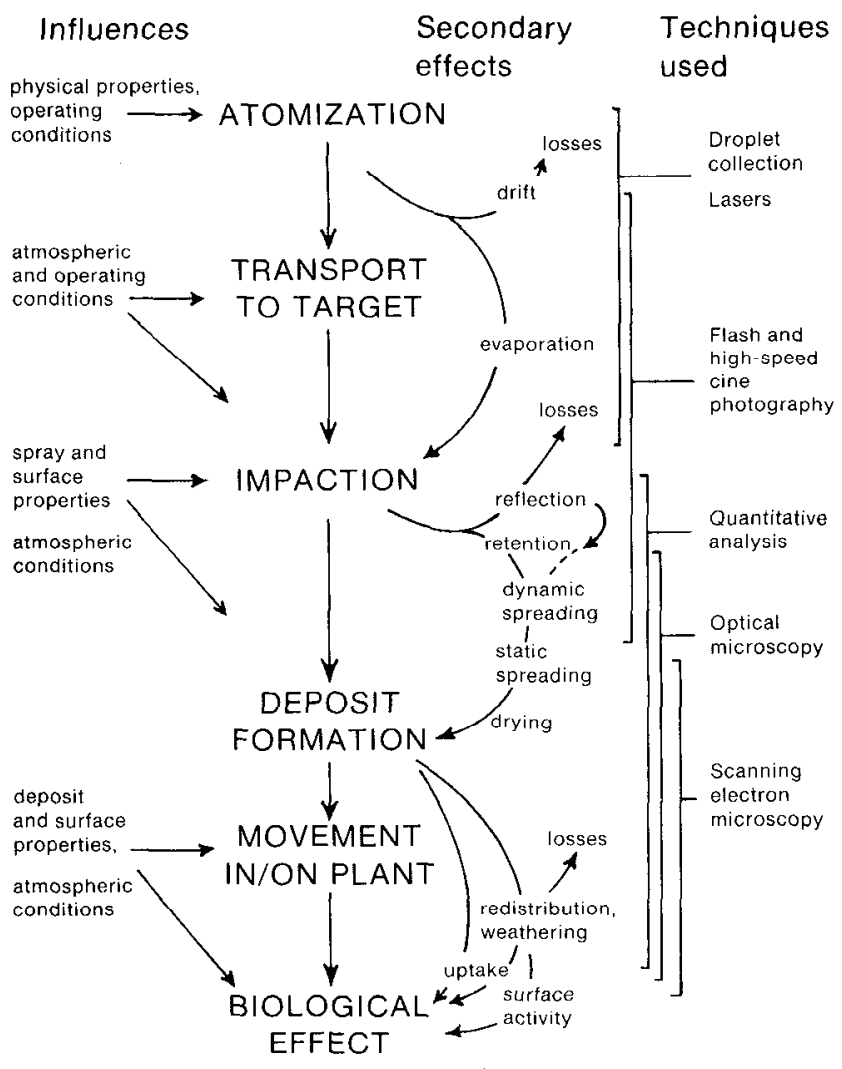

Fig. 1. The interactions of spray atomization (after Young, 1979).

public's concern about pesticides in the environment (and food safety) will force more growers into an action mode where they must demonstrate positive steps toward more enlightened pesticide management strategy. Federal regulatory initiatives may force increased pressure on pesticide management in controlling spray drift, installing buffer zones, posting lands, requiring improved worker exposure protection programs, restricting pesticide choices and use patterns, and developing a national training/certification effort for improving spray calibration and pesticide waste disposal routines.

\section{PLANT GEOMETRY/SPRAY COVERAGE INTERACTIONS}

Several recent studies have involved adjustments of pesticide rates/ volumes according to the type of planting. As we increase the proportion of high-density orchards by means of dwarfing rootstocks, it makes sense to ask, Do we need the same amount of material per hectare as in our standard plantings? The following studies are part of an ongoing program in Ohio and other states designed to increase the precision of pesticide application in orchards. As noted by Ferree and Hall (1980), there are significant differences in trunk cross section, canopy volume per tree (and per hectare) and leaf area per hectare among four apple management systems (Tables 1 and 2). Spray deposition studies showed that these high-density systems differ significantly in spray capture efficiency (Fig. 2), which reflects the differences in canopy volume, leaf area, and the amount of light interception by these canopies (Ferree and Hall, 1980; Hall, 1988). Average spray deposits were highest in the trellis trees, followed by slender spindle, interstem, and pyramid hedgerow tree systems. An evaluation of culled fruit from each of these systems indicated almost no cullage due to insect or disease damage. This result was of interest since the trellis and slender spindle trees had five to six times more spray deposit than the pyramid hedgerow trees in this experiment. The amount of spray volume and resulting deposition delivered to the pyramid system approximates the amounts used successfully to protect the system on a commercial basis. Thus, the increase in spray deposit within the other systems represents not only economic waste but unnecessary environmental entry and may also contribute to pest resistance.

Unless the pesticide delivery rates per foot for travel are adjusted, the denser plantings (with greater row footage per hectare) will automatically receive a higher spray volume and hence higher amounts of pesticide per hectare. The easiest adjustment for growers to make is a change in speed of travel within the different blocks. Thus, we adjusted the spray volume to 168 liter ha ${ }^{-1}$ for each planting in a subsequent experiment to account for differences in row spacing and meters of row per hectare. If there were no differences in tree canopy interception of sprays, then our deposition values should be about the same for each system. While higher deposits were received on the trellis system (Table 3 ) there was a reduction in the variation in pesticide deposits among systems as a result of the adjustments for each planting.

The more recent data from our laboratory reflect a change in spray deposition from standard trees at 19 trees/ha vs. an M9 planting at 98 trees/ha and M26 at 734 trees/acre. "In row" vs. "sprayer side" spray deposits are clearly differentiated, especially between plantings (Table 4). It is this difference that allows the use of alternate row techniques (ART) in IPM programs, e.g., the lower dosed areas of the unsprayed portion of the canopy leave places (refugia) for survival of predators. The data in Table 4 also indicate the problems that large canopies present when attempting to establish even coverage in orchard plantings.

Measurements of potential spray drift or off-target placement within these same blocks are presented in Table 5. Once again, denser plantings (M26) show higher deposits, hence greater capture efficiency than less dense arrangements. The closeness of adjoining canopies in the denser plantings also allows a greater potential for increasing next-row spray deposition, which is useful for ART practices.

A fluorescent dye (Rhodamine B) was used to track spray deposition in a study of the interaction of peach canopy management techniques and spray deposition (Table 6). As with apples, plant geometry as well as cultural techniques can play a significant role in ultimate pesticide deposition. Total average residues per system that had side mechanical shearing were highest in the fan system. The narrower canopy of the fan system also resulted in the highest spray deposition of these systems. Thus, it is clear that any significant change in the horticultural management of an orchard may

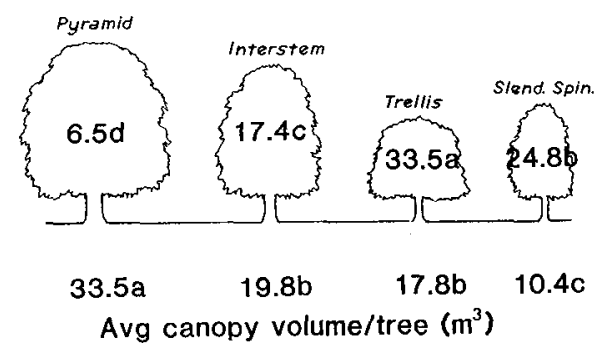

Fig. 2. Spray deposition efficiencies (Permethrin; mg/site) in four apple orchard management systems. Means separation for each system by Duncan's multiple range test, $P=0.05$. Application at 6.88 liter. $\mathrm{min}^{-1}$ in each system.

Table 1. Tree size, canopy volume, and cumulative yield of 6-year-old 'Golden Delicous' apple trees grown in four orchard management systems (after Ferree and Hall, 1980). ${ }^{\mathrm{Z}}$

\begin{tabular}{lcccc}
\hline \hline $\begin{array}{l}\text { Management } \\
\text { system }\end{array}$ & $\begin{array}{c}\text { Trunk } \\
\text { cross section } \\
\left(\mathrm{cm}^{2}\right)\end{array}$ & $\begin{array}{c}\text { Canopy } \\
\text { vol/tree } \\
\left(\mathrm{m}^{3}\right)\end{array}$ & $\begin{array}{c}\text { Canopy } \\
\text { vol/ha } \\
\left(1000 \mathrm{~m}^{3}\right)\end{array}$ & $\begin{array}{c}\text { Leaf area/ } \\
\mathrm{ha}^{y} \\
\left(1000 \mathrm{~m}^{3}\right)\end{array}$ \\
\hline $\begin{array}{l}\text { Slender spindle } \\
\begin{array}{l}\text { Trellis } \\
\text { Interstem } \\
\quad \text { hedgerow }\end{array}\end{array}$ & $41 \mathrm{c}$ & $10.4 \mathrm{c}$ & $22.4 \mathrm{a}$ & 27.7 \\
$\begin{array}{l}\text { Pyramid } \\
\text { hedgerow }\end{array}$ & $50 \mathrm{~b}$ & $17.8 \mathrm{~b}$ & $19.6 \mathrm{a}$ & 19.1 \\
\hline
\end{tabular}

${ }^{2}$ Mean separation within columns by Duncan's multiple range test, $P=$ 0.05 .

Calculated from entire tree leaf counts of four trees of each system. 
Table 2. Light and spray penetration in 7-year-old 'Golden Delicious' apple trees grown in four orchard management systems (after Ferree and Hall, 1980). ${ }^{2}$

\begin{tabular}{|c|c|c|c|c|c|c|c|c|}
\hline \multirow{3}{*}{$\begin{array}{l}\text { Management } \\
\text { system }\end{array}$} & \multicolumn{2}{|c|}{ Percent of full sun } & \multicolumn{6}{|c|}{ Developed canopy location percent of full sun } \\
\hline & \multirow{2}{*}{$\begin{array}{l}\text { Developing } \\
\text { canopy }\end{array}$} & \multirow{2}{*}{$\begin{array}{c}\text { Developed } \\
\text { canopy }\end{array}$} & \multicolumn{3}{|c|}{ North } & \multicolumn{3}{|c|}{ South } \\
\hline & & & Upper & Mid & Lower & Upper & Mid & Lower \\
\hline & \multicolumn{2}{|c|}{ Light } & \multicolumn{6}{|c|}{ Spray } \\
\hline & & 22 & 34 & 14 & 6 & 56 & 17 & 8 \\
\hline & & & 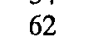 & 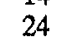 & 15 & & & 17 \\
\hline Inter & 28 & & 42 & 1 & 16 & 53 & 3 & 32 \\
\hline Pyramid hedgerow & $23 \mathrm{bc}$ & $25 \mathrm{bc}$ & 36 & 18 & 10 & 46 & 29 & 8 \\
\hline
\end{tabular}

${ }^{2}$ Mean separation within columns by Duncan's multiple range test, $P=0.05$.

Table 3. Deposition from adjusted spray delivery rates to account for differences in row spacings/row footage ${ }^{\mathrm{z}}$

\begin{tabular}{lcc}
\hline & $\begin{array}{c}\text { Average } \\
\text { carbaryl/site } \\
(\mu \mathrm{g})\end{array}$ & $\begin{array}{c}\text { Average canopy } \\
\text { density } \\
(\%)\end{array}$ \\
Orchard system & $459 \mathrm{a}$ & $75 \mathrm{bc}$ \\
Pyramid hedgerow & $565 \mathrm{ab}$ & $68 \mathrm{ab}$ \\
Interstem & $680 \mathrm{~b}$ & $64 \mathrm{a}$ \\
Trellis & $415 \mathrm{a}$ & $78 \mathrm{c}$ \\
Slender spindle & T1 &
\end{tabular}

"Mean separation in columns by Duncan's multiple range test, $P=0.05$. Arcsin transformations were made on percentage data before analysis. The retransformed data are presented.

Table 4. Orchard size and spray deposition.*

\begin{tabular}{|c|c|c|c|}
\hline \multicolumn{2}{|c|}{ Orchard and site } & $\begin{array}{c}\text { Average } \\
\text { carbaryl/50 } \\
\text { leaf disks } \\
(\mu \mathrm{g})\end{array}$ & $\begin{array}{l}\text { Overall mean } \\
\mu \mathrm{g} / \text { tree }\end{array}$ \\
\hline North & $\begin{array}{l}\text { Sprayer side } \\
\text { Tree row }\end{array}$ & $\begin{array}{l}2076 \mathrm{~b} \\
1236 \mathrm{c}\end{array}$ & 1656 \\
\hline M.9 & $\begin{array}{l}\text { Sprayer side } \\
\text { Tree row }\end{array}$ & $\begin{array}{l}2517 \mathrm{~b} \\
2157 \mathrm{~b}\end{array}$ & $2337(+41)$ \\
\hline M.26 & $\begin{array}{l}\text { Sprayer side } \\
\text { Tree row }\end{array}$ & $\begin{array}{l}3765 a \\
3110 a\end{array}$ & $3437(+107)$ \\
\hline
\end{tabular}

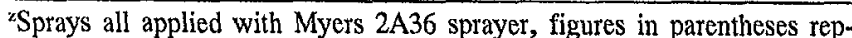
resent percentage increase over data for North orchard.

${ }^{y}$ Mean separation by Duncan's multiple range test, $P=0.05$.

Table 5. Spray deposition potential for alternate row spraying.

\begin{tabular}{lccr}
\hline & \multicolumn{3}{c}{\begin{tabular}{c} 
Average azinphosmethyl $(\mu \mathrm{g}) / 50$ leaf disks \\
\cline { 2 - 4 }
\end{tabular}} \\
\cline { 2 - 4 } Orchard & Sprayed row & (no.) \\
\hline North & 305 & 1 & 2 \\
M9 & 423 & 33 & 0 \\
M26 & 854 & 21 & 0 \\
\hline
\end{tabular}

${ }^{x}$ Myers $2 \mathrm{~A} 36$ airblast sprayer at $3.22 \mathrm{~km} \cdot \mathrm{h}^{-1}$ in each system with $3 \mathrm{X}$ material.

Table 6. Interception of fluorescent dye by three peach management systems with trees sheared or not sheared on sides.

\begin{tabular}{lrcc}
\hline \hline \multirow{2}{*}{$\begin{array}{l}\text { Training } \\
\text { system }\end{array}$} & \multicolumn{3}{c}{ Mean total $\mu \mathrm{g} /$ dye $\mathrm{cm}^{2} \times 10^{-3 \mathrm{z}}$} \\
\cline { 2 - 4 } & Sheared & Unsheared & Change (\%) \\
\hline Natural & $72.3 \mathrm{a}$ & $37.4 \mathrm{a}$ & -48.3 \\
Vase & $74.3 \mathrm{a}$ & $61.1 \mathrm{~b}$ & -17.7 \\
Fan & $161.1 \mathrm{~b}$ & $73.7 \mathrm{bc}$ & -54.2 \\
\hline
\end{tabular}

${ }^{2}$ Mean separation in columns by Duncan's multiple range test, $P=0.05$.

influence the level of spray deposition.

Alternate row techniques have a role in pest management, but tree geometry/canopy area can also influence the biological result. Hall (1984) demonstrated successful results with a 16,450 liter $\cdot \mathrm{sec}^{-1}$ sprayer at $\approx 1030$ liter $\cdot \mathrm{ha}^{-1}$ in an apple planting $6.6 \times 9$ $\mathrm{m}$ with trees $4.5 \mathrm{~m}$ high. All treatments were initiated after bloom on a 7- and 10-day schedule and no adjustments were made each year according to pest pressure.

The study showed that the sprayer's capacity to deposit sprays in 9-m tree plantings with some of the more dense cultivars was minimal but sufficient to maintain pest control. In this project, over a 5-year period, it was demonstrated that a low-volume, moderately sized sprayer can deliver pesticides in adequate levels to well-pruned apple trees, $\approx 4.5 \mathrm{~m}$ high, spaced 7 to $9 \mathrm{~m}$ in rows, without significant loss of pest control. Cost savings from an ART protocol are meaningful if there are no changes in either yield or quality. There is a potential for management error (missing a row, and/or not seeing a pest problem in time), and so there are risks in adopting this technique. Under an ART program, the grower must be able to recognize the need for adjustments following a proper identification of the problem. Adequate planning is essential, as ART protocols are not as easy as routine 2-week scheduling of plant protection measures. There are increased risks from a variety of sources and these alone can act as a major constraint to ART being an acceptable practice for many growers. With good management practices, these constraints are minimal. Enhancement of IPM strategies to maximize mite predator survival were of value, particularly in 1983, where several sprays for miticide alone accounted for expenditures as high as $\$ 20$ to $\$ 30 /$ ha.

Low-volume spraying has taken on practical significance in most apple areas of the United States. However, efficient low-volume spraying requires even greater accuracy in sprayer calibration, pesticide measurement, and application than does dilute spraying. A study of a standard sprayer (1403 liter-ha' ${ }^{-1}$ ) (low airflow) and an airshear sprayer (243 liter-ha') (high airflow) in a standard planting of apples $12 \times 12 \mathrm{~m}, 4.5 \mathrm{~m}$ high (canopy diameter of $6.7 \mathrm{~m}$ ), showed that differences in deposits throughout the tree (depending on site) were substantial (Hall et al. 1975). There was considerably less variation in initial deposits over all the sites on trees sprayed with the high-airflow-rate sprayer. Based on the 36 initial samples for each sprayer, the coefficients of variation (cv) were $68 \%$ and $133 \%$, respectively, for the residues from the high- and low-airflowrate sprayers. The high- and low-airflow-rate sprayers deposited $370 \%$ and $980 \%$ on sides nearest the sprayer (sites 1 through 4 ) than on opposite sides of the trees (sites 6 through 9). Mean deposits at site 5 in trees sprayed with the high- and low-airflow-rate sprayers were only $48 \%$ and $11 \%$, respectively, of those at site 1 . If trees were sprayed from both sides and each side received a distribution of deposits similar to those in this experiment, then the predicted cv would be $18.3 \%$ and $40.5 \%$, respectively, for all sites sprayed with the high- or low-airflow-rate sprayers.

Similar data were obtained by Reil et al. (1973) who demonstrated higher residues at the lower outside of trees. Carman et al (1972) also recorded higher residues from low-volume application at certain locations on the trees. Randall (1971) reported that the sprayer delivering the highest airflow rate produced the most uniform deposits throughout the trees, and the one delivering the lowest airflow rate deposited the most material on sites nearest the sprayers.

Steiner (1977) demonstrated that even under ideal conditions, as much as $30 \%$ to $45 \%$ of the spray can be lost to nontarget areas (Table 7 ). In addition, $\approx 25 \%$ more active ingredient per gram applied was received by the tree canopy under the 560 vs. 3742 liter.ha ${ }^{-1}$ procedure. However, it should also be recognized that the lower the spray volume (toward 93 to 187 liter-ha $^{-1}$ ), the higher 
Table 7. Distribution of pesticide deposits obtained with high volume (3742 liter $\left.\cdot \mathrm{ha}^{-1}\right)$ and low volume ( 560 liter $\left.\cdot \mathrm{ha}^{-1}\right)$ sprays used to apply the same amount of chemical/ha to a mature apple orchard in full leaf (after Steiner, 1977).

\begin{tabular}{lcc}
\hline \hline & \multicolumn{3}{c}{$\begin{array}{c}\text { Application rate } \\
\left.\text { (liter-ha }{ }^{-1}\right)\end{array}$} \\
\cline { 2 - 3 } sampling & \multicolumn{2}{c}{ Percentage deposited/g applied } \\
\hline Target areas & 44.3 & 560 \\
$\quad$ Foliage & 1.9 & 1.8 \\
Fruit & 8.4 & 9.7 \\
Bark & 54.6 & 69.8 \\
Total & 32.2 & \\
Nontarget areas & 13.2 & 24.3 \\
Ground & 45.4 & 5.9 \\
Other & & 30.2 \\
Total & & \\
\hline
\end{tabular}

${ }^{2}$ Represents all areas outside the treated orchard.

the variation in deposit, that is, it takes improved expertise and better weather conditions to deposit smaller droplets where they are needed. Finally, Uk and Courshee (1982) observed that variability in deposit negates achievement of an optimum biological effect. Thus, strategies that are aimed at reducing this variability should increase the efficiency of use of these limited resources (Bukovac, 1985).

Basic research on sprayer airflow behavior within canopies showed that tree foliage reduced air velocities in sprayer jets by deflecting, spreading, and absorbing the jet energy (Fox et al., 1984). At sites where we would expect $\approx 80 \mathrm{~km} \cdot \mathrm{ha}^{-1}$ air velocities without obstructions, only $19 \mathrm{~km} \cdot \mathrm{h}^{-1}$ was measured within the tree at top center and interior portions of the tree. To achieve more uniform coverage of spray materials over an entire tree, we must produce the optimum droplet-deposition velocity throughout the canopy. This goal may be accomplished by designing better sprayers, redirecting air flow, changing tree shape, or by other means, such as increasing the range of velocities that will effectively deposit droplets on plant surfaces. In addition, sprayers traveling at $6.4 \mathrm{~km} \cdot \mathrm{h}^{-1}$ produced air velocities $10 \%$ to $15 \%$ less than when traveling at $3.2 \mathrm{~km} \cdot \mathrm{h}^{-1}$. Additional increases in travel speed would further reduce sprayer-jet velocities. Previous research at our laboratory indicated that air jets are deflected more at higher travel speeds (Fox et al., 1982). Higher travel speed usually results in less uniform distribution of spray material over a tree than lower speed. While developing a computer model for sprayer travel speed and its influence on deflection of air flow, Fox et al. (1986) observed that sprayer travel can directly deflect air flow pathways and reduce the distance that sprays penetrate into canopies.

In summary, these and other studies (as outlined by Hall et al., 1988) suggest that tree height, planting distances, tree shape, growth (and seasonal) patterns, and the expertise of the operator to match the application with the target geometry, are all vital factors determining the efficiency of the spray application process. A mismatch of either one to adjust for changes in area and shape of foliar targets can result in the all-too-familiar comments of "overkill" or "the chemical did not work." Accurate control of travel speed and adjustment of liquid and air flow to the foliar target are critical for an efficient application. These adjustments are mandatory if one is to attempt fine tuning practices of IPM.

\section{IPM CONSIDERATIONS}

Pest control effectiveness is directly related to initial deposit and residual quantities of the pesticide on target surfaces. Knowledge of these factors is invaluable to those who design sprayers, make pest control recommendations, and establish safety rules for workers in orchards. Hoerger and Kenaga (1972) reported that if the spray volume is held below the point of significant runoff, the application of a pesticide to a given plant surface results in residues in direct proportion to the dosage, if other variables are similar. However, Young and Ditman (1963) demonstrated that a lower spray volume increased pesticide residues, but not proportionately with concentration. More recently, Hislop (1987) reported that frequently there is little correlation between spray deposition and biological results. Clearly, there is an urgent need for more fundamental information on targeting and factors governing pesticide placement in plant canopies. However, biologists also have to determine how much is needed, where, and at what time. This level of detail is not yet available. These and other research opportunities have been succinctly outlined (Bukovac, 1985; Hall, 1985; Agricultural Research Inst. Proceedings, 1988), suggesting that we have a tremendous opportunity to improve our understanding of the interactions involved in pesticide application. In view of the recent public concerns about food safety, groundwater quality, and the use of pesticides in general, it is obvious that we must accelerate the process, beginning at the grower level. Have we made optimal use of the tools currently available?

Pest decision computer models will add to understanding of timing, as will crop production records management (yield and quality relationships with inputs) as per the CASH MARKET MODEL (Hall et al., 1987). The examination of relationships that document the economic impacts for a block or orchard can thus 1) improve grower confidence about his operation, 2) encourage identification of the weak spots, and 3 ) reduce grower apprehension about potential changes in crop protection/production practices.

Experiences with IPM have shown that grower acceptance of an innovative practice depends on these interacting factors: 1) Economics is but one element; 2) must be compatible with current activities; 3 ) must have minimal perception of risk; 4) must be easily adopted; 5) must be associated with a reduction in crop losses or inputs; 6) must not require excessively increased management expertise/time; 7) must not depend on significant additional resources, such as labor and equipment; 8) must have a definable benefit to the grower.

Crop protection strategies assume an optimum production system that, for the myriad of growers, unique locations, and available resources, expertise and management experiences, just does not exist. As developers of new strategies and techniques for grower use, we need to understand the grower situation better. With improved knowledge of grower goals and constraints, one can then determine whether the limiting factors in the implementation of new strategies are time and available resources, management expertise, risk aversion, information availability (microcomputer predictions of pests, etc.), or flexibility in response tactics.

Caution must be exercised by researchers and developers of lower input (reduced pesticide) strategies because of the extremely high crop values and now (because of a lack of apple scab eradication materials) very susceptible commercial apple cultivars. The input costs for crop protection chemics on apples still remain $<10 \%$ of total crop production costs and with million dollar crops at risk, it makes little sense to experiment and not be able to recover from a miscalculation for the potential gain of $<1 \%$. However, there are real opportunities to tighten up pesticide use to the full advantage of the grower and the ecosystem. These opportunities should be fully explored.

\section{PRACTICAL CONSIDERATIONS/RECOMMENDATIONS}

Ecological selectivity (Hull and Beers, 1982) can be undertaken with the use of pesticides via pesticide management strategies such as: Choice of compound-sensitivity to predators; rates of useminimum rate coupled to pest pressure; timing-aided by pheromone traps, scouting programs, decision support systems; volume of delivery-optimally matching the sprayer and intended target(s); tree planting system-adjustments for cultural practices, ART; delivery system adjustments (per block)-for plant geometry, and seasonal growth; awareness of grower expertise and his risk aversiveness; willingness to manage (rather than insure)-innovativeness; knowledge of resources and financial status-information management. All of these strategies are achievable if growers will take the time to learn how to match the target and the spray effectively and then do it.

A definitive approach to more accurate tree spraying (tree row volume-TRV) was identified and evaluated [Sutton and Unrath, 1984; Byers et al., 1984]. However, Hall (1981, 1988) reported 
many Ohio growers were already below these guidelines. Thus, while TRV represents a guideline for adjustments, individual strategies for each grower and orchard take precedence. In addition, the use of ART is a valuable addition to grower strategies, provided that technical precision is well managed and there is adequate attention to crop loss assessment within the orchard (Hall et al., 1988). Other adjustments include starting dormant/green tip applications at $65 \%$ of full rates, $75 \%$ at pink, $85 \%$ at petal fall, and full volume rates from first cover throughout the remainder of the season.

A practical approach for improving spray application for various tree planting densities, etc. (Hall et al., 1988) includes the following simple steps: 1) Map the orchard by block and plan the application strategy for each block by cultivar, tree density, and production potential; 2) identify the spray output per unit area in each block according to the same factors; 3 ) for each combination of sprayer/ block, determine the noggle arrangement, the spray output per unit of time for each, and the total output for each speed of travel and pressure combination; 4) note the adjustments that can be made for each block; i.e., changes in liter $\cdot \sec ^{-1}$ with one to four nozzles shut off; changes in liter-ha-1, with speed increase/decrease; pressure adjustments, and alternate-middle applications; 5) record the details on a flip card system and place the cards on a rack next to the tractor seat. This nozzle chart would thus designate for each block the nozzle-disc combination and their liter $\cdot \sec ^{-1}$ output for selected pressures and travel speeds; 6) record the last date of sprayer calibration on a sticker placed on the control panel of the sprayer ( $\log$ the details in a separate record book).

Again, unless predetermined adjustments are made in the speed of travel and other factors to account for reduced tree size, increased row meters, tree capture efficiency because of cultivar or pruning practices, etc., there is likely to be increased pesticide deposition in the higher tree density plantings. Any one of the aforementioned steps requires only two things: 1) that the grower know what happens with the adjustment, and 2) that the operator get down off the tractor seat in different blocks and do it. Such adjustments are aided by the use of food dyes or fluorescent tracers and cards placed in trees to establish spray patterns within different blocks, It may only take $10 \mathrm{~min} / \mathrm{block}$ to improve the precision of pesticide application in that block, but the orchardist has to take the time to do it.

The use of variable rates in one block vs. another, depending on the pest situation or cultivar susceptibility, is also a more rational strategy for the use of pesticides. Serious consideration must be given to the potential of variable rates because of their cost-reducing values, and enhancement of IPM strategies. However, with some of the current spray machinery, it is cumbersome and time consuming to make these adjustments. Or is it? The nozzle disc/core combinations can be "charted" in the spring. So when nozzles 1,2 , and 9 are shut off, for example, it is a reduction of $10 \%$ or $20 \%$ in output. Tree height can be accomodated by changing the air flow patterns, or, in the case of low-volume equipment, the flow rate dials can be changed. The pressure and speed of travel can be adjusted (if they have functional gauges) or alternate row procedures can be used.

New technology may involve electrostatics and electronic sensors to aid the targeting of our chemical crop protection tools. There are now spray monitors that are very useful in keeping the applicator aware of the state of the application process and insuring that what was intended (rate of application) is indeed happening. Rather than a single-point source atomizer, a series of atomizers placed closer to the entire plant canopy via vertical (or movable) booms can indeed place more toxicant in critical (quality fruit) areas of pyramid or hedgerow trees (F.R.H., unpublished data). Crossflow fans and adjustable flow patterns up to $45^{\circ}$ backward (vs. the standard $90^{\circ}$ ) have proven to have useful canopy deposition benefits depending on the width of the canopy. Investigations are continuing on the development of a pesticide rate based on amount per $1000 \mathrm{~m}^{3} \mathrm{can}-$ opy per $30 \mathrm{~m}$ row, i.e., a rate per sprayed area as suggested by Morgan (1964) and Hall and Reichard (1978) in an attempt to reinforce a targeting concept that is applicable to all types of crops. Increased attention to the problem of orchard drift by regulatory officials has resulted in increased research on over-row and recap- ture technologies. However, it has also been well documented (Hall, 1985; ARI, 1988) that growers are not taking full advantage of what they already have on hand. Thus, the simple, practical suggestions as above, if practiced by the average grower, could save them $20 \%$ to $40 \%$ of the expense over current practices. Too many are using these very effective chemicals as a crutch. Future regulatory actions may limit the use of chemical tools to those users who demonstrate ecological, economic, and safety precautions are being practiced, i.e., prescription only.

Growers frequently state that they are spending too much on crop protection chemicals, but they are unable to estimate the expenditure of dollars per hectare or per packed box, or the scale of block and cultivar productivity, quality, and profitability. If application costs are examined in relation to production units, i.e., crop yields and quality, it is easy to translate pesticide use to costs and benefits per unit of production $\left(\mathrm{t} \cdot \mathrm{ha}^{-1}\right)$. These data directly tell the story of cost effectiveness of the pesticide and its application process from which growers can better plan future strategies for crop protection. Coupled with the use of on-farm decision aids such as MARKET MODEL (Hall et al., 1987), increased information about relationships between production costs and benefits will greatly decrease the reliance on additional sprays as "insurance" as well as the perception of increased risk associated with any change in a crop protection strategy.

\section{CONCLUSIONS}

Growers can do much with what they already have on the farm. Although airblast sprayers are not very easy to adjust, there are operations that can be accomplished to improve delivery to the arrays of tree canopies and geometries. The problem is making growers aware of the need to do so and the potential that exists for their operation by: 1) matching sprayer delivery/canopy geometry for each block; 2) developing a block-by-block crop protection strategy (the variation in cultivar susceptibility/tolerance to various pests is under-used by most growers); 3) improving grower appreciation for information management and knowledge of production/price relationships and crop losses on their farm to optimize pesticide management in their orchard.

Keeping pesticides on target, i.e., defining that target, and making appropriate adjustments in spray delivery protocols, is going to be a very important issue for the tree fruit grower in the 1990s. Faced with increasing spray costs and regulations, management strategies that address these issues will clearly pay dividends for the grower who is willing to invest the management expertise to solve these problems.

\section{Literature Cited}

Agricultural Research Institute. 1988. Improving on-target placement of pesticides. Proc. Conf. by Agr. Res. Inst. (ARI), Bethesda. Md. 220 p. Bukovac, M.J. 1985. Spray application technology: shortcomings and opportunities with special reference to tree fruits. Proc. Conf. by Agr. Res. Inst. Bethesda, Md. p. 25-38.

Byers, R., C. Lyons, K. Yoder, R. Horsburgh, J. Barden, and S. Donohue. 1984. Effect of apple tree size and canopy deposit on spray chemical deposit. Proc. Application Agr. Chem. to Tree Fruits with Ground Equipment. K. Hickev (ed.). 18-19 Dec. 1984. Harpers Ferry. W. Va.

Carman, G.E., W.E. Westlake, and F.A. Gunther. 1972. Potential residue problem associated with low volume sprays on citrus in California. Bul. Environ. Contam. Toxicol. 8:38.

Ferree, D. and F. Hall. 1980. Canopy development, light and spray penetration in golden delicious trees in four management systems, Acta Hort. 114:91-99.

Fisher, R.W. 1970. Problems associated with spraying large trees in Ontario apple orchards. Entomol. Soc. Ontario Proc. 101:35-40.

Forshey, C.G., R.W. Weires, B.H. Stanley, and R.C. Seem. 1983. Dry weight partitioning of "McIntosh" apple trees. J. Amer. Soc. Hort. Sci. 108:149-154.

Fox, R.D., R.D. Brazee, and D.L. Reichard. 1986. Air sprayer jet deflection by travel or wind: as predicted by computer. Ohio Agr. Res. and Dev. Ctr. Res. Cir. 290.

Fox, R.D., D.L. Reichard, and R.D. Brazee. 1982. A model study of the effects of wind on air sprayer jets. Ohio State Univ., Ohio Agr. Res. and Dev. Ctr. Res. Cir. 272. p. 25-28. 
Fox, R.D., D.L. Reichard, R.D. Brazee, and F.R. Hall. 1984. Penetration of an apple tree canopy by orchard-sprayer air jets. Ohio State Univ., Ohio Agr. Res. and Dev. Ctr. Res. Cir. 283:22-25.

Graham-Bryce, I. 1983. Pesticide research for the improvement of human welfare. Proc. 5th Intl. Congr. Pesticide Chem. 1:21-42.

Geissbuhler, H., C. d'Handt, E. Kunz, R. Nyfeler, and K. Pfister. 1986. Reflections on the future of chemical plant protection research. Proc. 6th Intl. Congr. Pesticide Chem.. Blackwell, 1:3-14.

Hall, F. 197\%. The need for innovative pesticide research in fruit production. Insect and Acaracide Tests 4:4-7.

Hall, F.R. 1981. Spraying efficiency revisited. Fruit Grower June:12, 24.

Hall. F. 1984. Evaluation of alternate row middle (ARM) for apple orchards. Ohio State Univ., Ohio Agr. Res. Dev. Ctr. Res. Cir. 283:17-21.

Hall, F.R. (ed.) 1985. Improving agrochemical and fertilizer application technology. Proc. Conf. by Agr. Res. Inst., Bethesda, Md.

Hall, F.R., D. Ferree, D. Reichard, and H. Krueger. 1988. Orchard geometry and pesticide deposition efficiency. Fruit crops 1987: A summary of research. Ohio Agr. Res. Dev. Ctr. Res. Cir. 295:23-27.

Hall, F.R., J.R. Lemon, and R.C. Funt. 1987. Cash in on CASH. Amer. Fruit Grower, March:52-53.

Hall, F.R., D.L. Reichard, and H.R. Krueger. 1975. Dislodgeable azinphosmethyl residues from airblast spraying of apple foliage in Ohio. Arch. Environ. Contam. 3:352-362.

Hall, F. and D. Reichard. 1978. Keeping pesticide application on target. Amer. Fruit Grower, June:21.

Hess, C. 1987. Agricultural technology and society. Proc. Ohio State Univ. Battelle Endowment for Technol. \& Human Affairs. 1:1-27.
Hislop, E.C. 1987. Can we define and achieve optimum pesticide deposits? Aspects of Biology 14:153-172.

Hoerger, F. and E. Kenaga. 1972. Pesticide residues on plants: correlation of representative data as a basis for estimation of their magnitude in the environment. Environ. Quality and Safety 1:9.

Hull, L. and E.H. Beers. 1985. Ecological selectivity: modifying chemical control practices to preserve natural enemies. Biological control in agricultural IPM systems. p. 103-122.

Morgan, N.G. 1964. Gallons per acre of sprayed area. World Crops June:6465 .

Randall, J.M. 1971. The relationship between air volume and pressure on spray distribution on fruit trees. J. Agr. Eng. Res. 16:1-31.

Reil, W., J. Bertel, and W. Moller. 1973. Use of spray target cards and leaf analysis to measure spray coverage. Calif. Agr. 27:7.

Steiner, P.W. 1977. Factors affecting the efficient use of orchard airblast sprayers. Proc. Ill. State Hort. Soc. 110:57-64.

Sutton, T. and C. Unrath. 1984. Evaluation of the tree row-volume concept with density adjustments in relation to spray deposits in apple orchards. Plant Dis. 68(6):480-484.

Uk, S. and R.J. Courshee. 1982. Distribution and likely effectiveness of spray deposits within a cotton canopy from fine ultralow-volume spray applied by aircraft. Pesticide Sci. 13:529-536.

Young, B.W. 1979. Paper presentation at the 1979 Congress Internationale de Genie Rural (CIGR), E. Lansing, Mich.

Young, T. and L. Ditman. 1963. Factors influencing pesticide deposits on leaf surfaces. Univ. of Maryland Bul. A-132. 